14

\title{
Исследование механических характеристик нативных фибробластов с помощью атомно-силового микроскопа
}

\author{
() К.И. Тимощук ${ }^{1}$, М.М. Халисов ${ }^{1}$, В.А. Пеннияйнен ${ }^{1}$, Б.В. Крылов ${ }^{1}$, А.В. Анкудинов ${ }^{2, \text { ॠ }}$ \\ ${ }^{1}$ Институт фризиологии им. И.П. Павлова РАН, Санкт-Петербург, Россия \\ ${ }^{2}$ Физико-технический институт им. А.Ф. Иофрфе РАН, Санкт-Петербург, Россия \\ ฯ E-mail: alexander.ankudinov@mail.ioffe.ru
}

Поступило в Редакцию 16 мая 2019г.

В окончательной редакции 16 мая 2019г.

Принято к публикации 13 июня 2019 г.

\begin{abstract}
Обнаружено упрочнение фибробластов после воздействия колхицина. Для достоверных измерений были идентифицированы клетки, при индентации которых латеральная сила взаимодействия не искажает вклад нормальной силы. Данные атомно-силовой микроскопии механических характеристик таких клеток трактуются однозначно.
\end{abstract}

Ключевые слова: атомно-силовая микроскопия, фибробласты, колхицин.

DOI: 10.21883/PJTF.2019.18.48238.17878

Атомно-силовая микроскопия (ACM) активно применяется для изучения механических свойств нативных клеток [1-5]. До сих пор, однако, актуальна проблема согласования результатов разных исследователей, например, по определению модуля Юнга клеток, и значительные усилия направлены на стандартизацию таких измерений [6].

В АСМ механические свойства образца определяются путем его индентации и анализа полученной нагрузочно-разгрузочной зависимости. Существенный вклад в результат измерений может вносить трение в контакте зонд-образец. Важно учесть, скользит или защемлен зонд на образце. В первом случае приложенная к кончику зонда кантилевера сила действует по нормали к поверхности образца и изгибает консоль кантилевера так, что угол изгиба монотонно возрастает (или убывает) вдоль консоли [7]. Во втором случае добавляется латеральная компонента силы трения, из-за которой консоль прогибается (угол прогиба меняется немонотонно) $[7,8]$. В большинстве атомно-силовых микроскопов контролируется не профиль угла отклонения консоли, а значение угла в единственной точке - фокусе лазера системы регистрации деформаций кантилевера. Из-за этого система управления прибором не отличает прогиб консоли от изгиба $[9,10]$, что ведет к ошибкам измерений амплитуды и направления силы индентации.

Ранее на сенсорных нейронах было показано, что их кажущийся модуль Юнга $E_{A}$ падает с ростом $\lambda$ (отношения высоты зонда к длине консоли используемого кантилевера), что связывалось с защемлением контакта зонд-клетка [8]. В таком случае $E_{A}$ зависит и от твердости нейрона, и от трения в контакте. Например, при постоянном трении рост $E_{A}$ вызван ростом твердости, а при постоянной твердости - падением трения. Такой неоднозначности нет, когда зонд скользит по объекту исследования, и $E_{A}$ перестает зависеть от $\lambda$. Связь $E_{A}(\lambda)$ описывает среднестатистический объект и определяется по большому объему данных, полученных кантилеверами с различными значениями $\lambda[8]$.

Надежность измерений проверяют на клетках, обработанных агентами, влияющими на компоненты внутриклеточных структур, и контрольных клетках. Так, цитохалазин, деполимеризуя актиновый цитоскелет, должен смягчать клетку, и изучается соответствие с этим [11]. В свою очередь достоверные АСМ-измерения ценны для понимания деталей молекулярных и клеточных механизмов, запускаемых исследуемыми субстанциями.

В настоящей работе предлагается идентифицировать скольжение АCM-зонда на клетке по росту сигнала деформации на ее наклоненных границах. Используя этот способ, удалось достоверно зарегистрировать увеличение твердости фибробластов после воздействия колхицина, способствующего деполимеризации тубулиновых микротрубочек.

Нативные фибробласты 10-12-дневных куриных эмбрионов готовились по ранее описанному протоколу [12]. Колхицин в культуральную среду добавляли в концентрации $0.1 \mu \mathrm{g} / \mathrm{ml}$ за сутки до измерений. Эксперименты велись при температуре $37^{\circ} \mathrm{C}$ на атомно-силовом микроскопе BioScope Catalyst (Bruker), встроенном в оптический микроскоп Axio Observer Z1 (Carl Zeiss). Для АСМ-индентирования и картирования механических характеристик клеток использовался режим PeakForce QNM и кантилеверы CSG10 (NT-MDT SI), коэффициент жесткости которых калибровался методом тепловых шумов. Также у прижизненно окрашенных фибробластов на конфокальном микроскопе LSM 710 (Carl Zeiss) контролировалась интенсивность флуоресценции актиновых волокон.

На рис. 1 показаны результаты АСМ-исследования фибробласта: изображение рельефа и карт сигналов кажущихся модуля Юнга и деформации, определенных по модели Снеддона. Термин „кажущийся“ подчеркивает, что сигналы формально описывают индентационную 
силовую кривую (например, такая деформация может регистрироваться на недеформируемом образце). Согласно профилям высоты и деформации на рис. 1, $a$ и $c$,
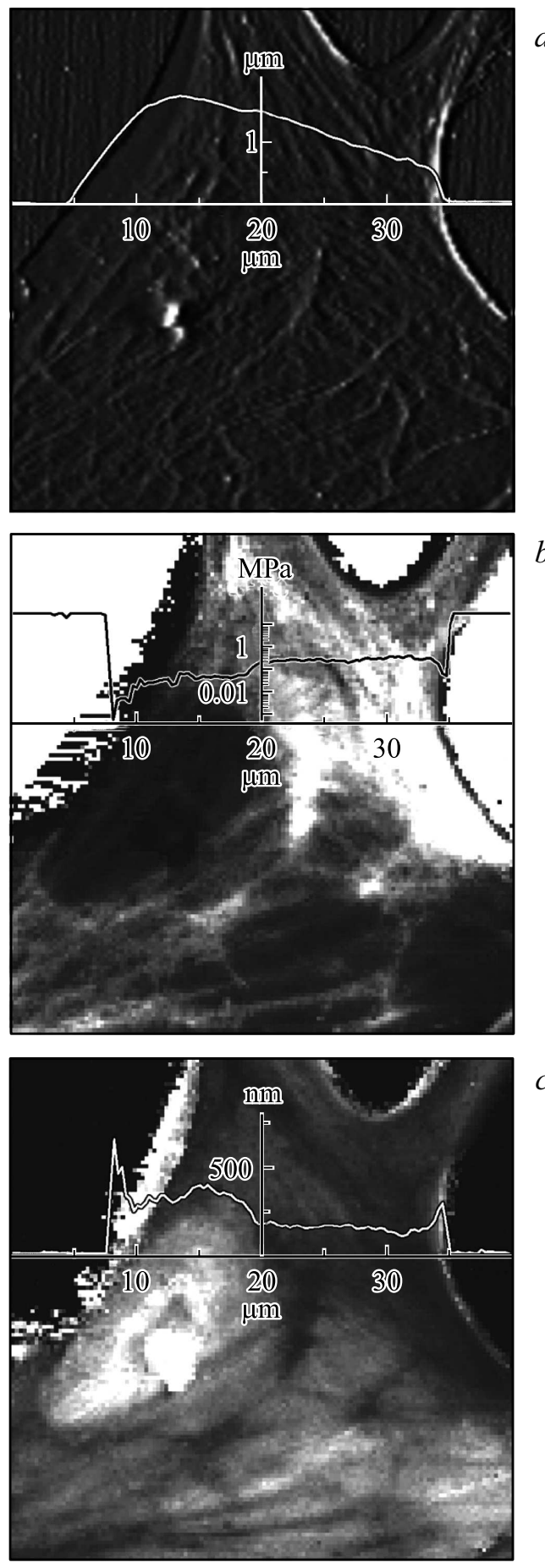

Рис. 1. АСМ-данные контрольного фибробласта: градиентное изображение рельефа с профилем высоты $(a)$ и тоновые изображения сигналов $E_{A}(b)$ и $D_{A}(c)$ с профилями сигналов. Средние сигналы на фибробласте: $E_{A}=120 \pm 80 \mathrm{kPa}$, $D_{A}=250 \pm 80 \mathrm{~nm}$. Режим PeakForce QNM. Параметры: питательная среда, $T=37^{\circ} \mathrm{C}, 128 \times 128$ точек, вертикальное зондирование на частоте $250 \mathrm{~Hz}$, амплитуда $1 \mu \mathrm{m}$, пиковая сила $3 \mathrm{nN}$, частота строчной развертки $0.15 \mathrm{~Hz}$.

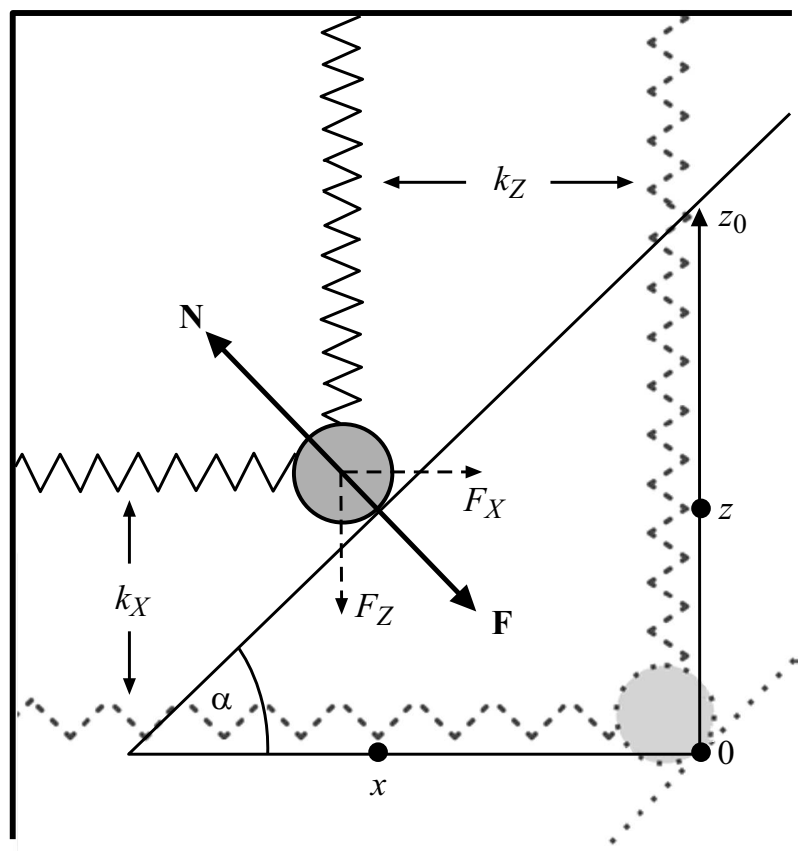

Рис. 2. Проскальзывание на наклоненном образце модельного кантилевера из двух пружин. Исходно кантилевер и образец изображены пунктиром. После подъема образца на высоту $z_{0}$ шарик-зонд проскальзывает по образцу в конечное положение $x$ и $z$. Реакция опоры $\mathbf{N}$ компенсируется силой давления кантилевера $\mathbf{F}$.

пики деформации возникают на склонах фибробласта. Левый пик выше правого, что связано с невязкой регулирования силы индентации, положительной на подъеме и отрицательной на спуске зонда с объекта. В АCM чем тоньше слой мягкого материала на твердой подложке, тем материал кажется тверже [13]. Несмотря на это, по всему периметру клетки отмечается рост сигнала деформации и соответствующее ему падение сигнала модуля Юнга (рис. 1, с и $b$ ).

На рис. 2 АСМ-кантилевер условно заменен горизонтальной и вертикальной пружинами (с коэффициентами жесткости $k_{X}$ и $k_{Z}$ ). Один конец пружин закреплен на шарике-зонде, а другой может скользить по противоположной стенке. Сначала шарик покоится в точке 0 на скользком наклоненном образце. Если поднять образец на высоту $z_{0}$, зонд соскользнет на уровень $z$, и появится кажущаяся деформация образца: $z_{A}=z_{0}-z$. В АСМ регулируется только сигнал вертикальной силы взаимодействия: $F_{Z}=k_{Z} z$. Считая для простоты $k_{A}=F_{Z} / z_{A}$ кажущейся жесткостью образца, можно показать, что конструкция на рис. 2 работает так, что $z=z_{0} k_{X} /\left(k_{X}+k_{Z} \operatorname{tg}^{2} \alpha\right), z_{A}=z_{0} k_{Z} /\left(k_{Z}+k_{X} \operatorname{ctg}^{2} \alpha\right)$ и $k_{A}=k_{X} \operatorname{ctg}^{2} \alpha$.

Предположим, что объект не деформируется. В АСМ на его скользких склонах тем не менее будет детектироваться кажущаяся деформация (жесткость), растущая (падающая) с увеличением угла наклона $\alpha$. Поскольку $E_{A}$ мало при малых $k_{A}$, на склонах сигнал $E_{A}$ ниже, чем 
Реакция нативных фибробластов на колхицин

\begin{tabular}{|c|c|c|c|c|c|c|c|c|c|}
\hline \multirow{2}{*}{$\begin{array}{l}\text { № } \\
\Pi / \Pi\end{array}$} & \multicolumn{3}{|c|}{ „Без сортировки“ } & \multicolumn{3}{|c|}{ „Скользкие“ } & \multicolumn{3}{|c|}{ „Липкие“ } \\
\hline & $E / E_{0}$ & $D / D_{0}$ & $\begin{array}{c}n ; n_{0}, \\
\text { шт. }\end{array}$ & $E / E_{0}$ & $D / D_{0}$ & $\begin{array}{c}n ; n_{0}, \\
\text { шт. }\end{array}$ & $E / E_{0}$ & $D / D_{0}$ & $\begin{array}{c}n ; n_{0} \text {, } \\
\text { шт. }\end{array}$ \\
\hline 1 & 2.19 & 0.82 & $6 ; 5$ & 1.66 & 0.81 & $4 ; 2$ & 3.26 & 0.83 & $2 ; 3$ \\
\hline 2 & 2.00 & 0.60 & $6 ; 3$ & 1.43 & 0.52 & $2 ; 3$ & $(-)$ & $(-)$ & $4 ; 0$ \\
\hline 3 & 1.20 & 0.95 & $7 ; 5$ & 1.16 & 1.08 & $5 ; 3$ & 1.31 & 0.74 & $2 ; 2$ \\
\hline 4 & 1.75 & 0.89 & $6 ; 6$ & 1.75 & 0.89 & $6 ; 6$ & $(-)$ & $(-)$ & $0 ; 0$ \\
\hline 5 & 0.92 & 0.93 & $9 ; 8$ & 0.83 & 0.87 & $6 ; 5$ & 1.46 & 1.04 & $3 ; 3$ \\
\hline 6 & 1.14 & 0.98 & $7 ; 7$ & 1.14 & 0.96 & $3 ; 4$ & 1.18 & 0.96 & $4 ; 3$ \\
\hline 7 & 1.16 & 0.71 & $7 ; 7$ & 2.00 & 0.73 & $5 ; 5$ & 0.85 & 0.63 & $2 ; 2$ \\
\hline 8 & 1.14 & 0.95 & $7 ; 7$ & 1.35 & 1.06 & $2 ; 2$ & 1.02 & 0.92 & $5 ; 5$ \\
\hline 9 & 1.40 & 0.95 & $8 ; 7$ & 1.33 & 0.90 & $3 ; 5$ & 1.42 & 0.94 & $5 ; 2$ \\
\hline$C$ & $\begin{array}{l}1.43 \pm \\
0.44\end{array}$ & $\begin{array}{l}0.86 \pm \\
0.13\end{array}$ & $\begin{array}{c}63 \\
55\end{array}$ & $\begin{array}{l}1.41 \pm \\
0.36\end{array}$ & $\begin{array}{l}0.87 \pm \\
0.17\end{array}$ & $\begin{array}{l}36 \\
35\end{array}$ & $\begin{array}{l}1.50 \pm \\
0.81\end{array}$ & $\begin{array}{l}0.87 \pm \\
0.14\end{array}$ & $\begin{array}{l}27 \\
20\end{array}$ \\
\hline
\end{tabular}

Пр и м е ч н и е. Нижний индекс $0-$ контрольные клетки, $(-)-$ нет данных. Все эксперименты велись с пиковой силой 3 nN. B последней строке $C$ приведены средние отношения по девяти экспериментам, а также количество клеток.

на горизонтальных участках. Темные, как на рис. $1, \quad b$, границы объекта в сигнале $E_{A}$ и светлые, как на рис. $1, c$, в сигнале деформации можно наблюдать, например, на калибровочной решетке квадратных выступов TGQ1 (NT-MDT SI).

Рис. 2 наглядно поясняет боковое проскальзывание зонда (ось $X$ поперек кантилевера), но не фронтальное (ось $X$ вдоль кантилевера). Поскольку данные рис. 1 получены кантилевером, ориентированным вдоль вертикальной стороны кадра, поведение деформации и модуля Юнга на склонах клетки в основном вызвано боковым проскальзыванием.

Далее фибробласт считался „скользким“, если кажущаяся деформация (модуль Юнга) возрастала (падал) на его границе. Для мягкого объекта (с жесткостью, меньшей, чем у кантилевера) можно аналитически показать рост кажущейся деформации и при боковом, и при фронтальном проскальзывании. Точный анализ должен также учесть конкурирующее падение деформации на границе мягкого объекта вблизи твердой подложки. Подробно вопрос будет рассмотрен в отдельной публикации.

В таблице приведены результаты девяти пар АСМ-экспериментов, тестирующих действие колхицина на фибробласты. Деформация и модуль Юнга усреднены по средним сигналам на поверхности фибробластов, участвующих в эксперименте (границы клеток исключались). Оказалось, что кремниевые АСМ-зонды скользят на $60 \%$ фибробластов. У таких клеток отношение кажущегося модуля Юнга после действия колхицина к контрольному значению $\left(E / E_{0}\right)$ однозначно отражает рост твердости фибробластов.

$\mathrm{У}$,липких“ клеток среднее $E / E_{0}$ на $\sim 6 \%$ выше, чем у „скользких“, что может быть вызвано как бо́льшим упрочнением „липких“ клеток, так и снижением трения зонда на них. Отличие, однако, незначимо: по тесту Манна-Уитни вероятность совпадения распределений больше 0.95. В исследовании фибробластов пирамидаль- ными нанометровоострыми и сферическими субмикронными зондами [12] было показано, что количественно состояние этих клеток лучше анализировать по сигналу деформации. Средние отношения $D / D_{0}$ у ,липких“ и „скользких“ фибробластов равны (см. таблицу). Поэтому в итоге мы предполагаем, что эффект колхицина заключается только в росте твердости клеток.

Измерения интенсивности флуоресценции выявили рост содержания $F$-актина в клетках после воздействия колхицина (аналогичный результат для фибробластов Swiss 3T3 обсуждался в [14]). Это свидетельство увеличения количества актиновых волокон в фибробластах из-за колхицина объясняет наблюдаемый рост твердости клеток. Следует добавить, что схожее действие колхицина уже обсуждалось в АСМ-исследовании нефроцитов (VERO) и клеток гепатомы (SMMC-7721) [5].

B заключение подчеркнем важность рассмотренного способа классификации нативных клеток по АСМ-данным в зависимости от вклада сил трения во взаимодействие зонд-клетка на „скользкие“ и ,липкие“. С его помощью достоверно выявлено упрочнение нативных фибробластов из-за колхицина. В будущем интересно изучить данный эффект для разных концентраций колхицина.

\section{Благодарности}

Авторы благодарны В.П. Ширинскому за предоставление колхицина.

\section{Финансирование работы}

Авторы, сотрудники Института физиологии им. И.П. Павлова РАН, благодарят программу фундаментальных научных исследований государственных академий наук на 2013-2020 гг. (ГП-14, раздел 64) и Российский фонд фундаментальных 
исследований (грант № 18-015-00079) за финансовую поддержку работы.

\section{Конфликт интересов}

Авторы заявляют, что у них нет конфликта интересов.

\section{Список литературы}

[1] Kuznetsova T.G., Starodubtseva M.N., Yegorenkov N.I., Chizhik S.A., Zhdanov R.I. // Micron. 2007. V. 38. N 8. P. 824 833. DOI: 10.1016/j.micron.2007.06.011

[2] Ren J., Huang H., Liu Y., Zheng X., Zou Q. // PLoS ONE. 2015. V. 10. N 5. P. e0126107.

[3] Haase K., Pelling A.E. // J. Roy. Soc. Interface. 2015. V. 12. P. 20140970.

[4] Lekka M. // BioNanoSci. 2016. V. 6. N 1. P. 65-80. DOI: 10.1007/s12668-016-0191-3

[5] Liu L., Zhang W., Li L., Zhu X., Liu J., Wang X., Song Z., $X u$ H., Wang Z. // J. Biomech. 2018. V. 67. P. 84-90. DOI: 10.1016/j.jbiomech.2017.11.018

[6] Schillers H., Rianna C., Schäpe J., Luque T., Doschke H., Wälte M., Uriarte J.J., Campillo N., Michanetzis G.P.A., Bobrowska J., Dumitru A., Herruzo E.T., Bovio S., Parot P., Galluzzi M, Podestá A., Puricelli L., Scheuring S., Missirlis Y., Garcia R., Odorico M., Teulon J.M., Lafont F., Lekka M., Rico F., Rigato A., Pellequer J.L., Oberleithner H., Navajas D., Radmacher M. // Sci. Rep. 2017. V. 7. N 1. P. 5117. DOI: $10.1038 / \mathrm{s} 41598-017-05383-0$

[7] Sarid D. Exploring scanning probe microscopy with MATHEMATICA. 2nd ed. Weinheim: WILEY-VCH Verlag, 2007. $310 \mathrm{p}$.

[8] Анкудинов А.В., Халисов М.М., Пеннияйнен В.А., Подзорова С.А., Тимошук К.И., Крылов Б.В. // Письма в ЖТФ. 2018. T. 44. B. 15 . C. $38-45$.

DOI: 10.21883/PJTF.2018.15.46438.17351

[9] Fujisawa S., Ohta M., Konishi T., Sugawara Ya., Morita S. // Rev. Sci. Instrum. 1994. V. 65. N 3. P. 644-647.

DOI: $10.1063 / 1.1145131$

[10] Kawakatsu H., Bleuler H., Saito T., Hiroshi K. // Jpn. J. Appl. Phys. 1995. V. 34. Pt 1. N 6B. P. 3400-3402.

DOI: 10.1143/JJAP.34.3400

[11] Rotsch C., Radmacher M. // Biophys J. 2000. V. 78. N 1. P. 520-535.

[12] Халисов М.М., Анкудинов А.В., Пеннияйнен В.А., Няпшаев И.А., Кипенко А.В., Тимошук К.И., Подзорова С.А., Крылов Б.В. // Письма в ЖТФ. 2017. Т. 43. В. 4. С. 56-63.

[13] Gavara N., Chadwick R.S. // Nature Nanotechnol. 2012. V. 7. N 11. P. 733-736.

[14] Jung H.I., Shin I., Park Y.M., Kang K.W., Ha K.S. // Mol. Cells. 1997. V. 7. N 3. P. 431-437. 